\title{
Универсальный подход к автоматическому трехмерному геологическому картированию
}

Калашников А.О.

Геологический институт КНЦ РАН, Anamuты, kalashnikov@geoksc.apatity.ru

Аннотация. Описан подход к автоматическому трёхмерному геологическому картированию, годный для разных типов данных, рудных объектов разного генезиса и строения. Его суть состоит в следующем: выделение переменных, достаточно точно определяющих тип пород; геостатистический анализ и интерполяция этих переменных в единую блочную модель; нахождение функции, переводящей эти переменные в типы пород, и ее приложение к блочной модели; визуализация. Предлагаемый подход можно использовать для минералогических и геохимических данных; для случаев, когда имеются эталонные выборки типов пород и когда таких выборок нет; также возможно картирование разрывных нарушений. Разработанный подход апробирован на трех рудных объектах различного строения и генезиса: Ковдорском бадделеит-апатит-магнетитовом месторождении (фоскорит-карбонатитовый шток), Ловозерском эвдиалитовом месторождении (лополит нефелиновых сиенитов) - Мурманская область, Большетроицком месторождении богатых железных руд (кора выветривания железистых кварцитов, Белгородская область).

Ключевые слова: геологическое картирование, рудные месторождения, Ковдорский массив, Ловозерский массив, Белгородский железорудный район.

\section{A universal approach to the automatic 3D geological mapping}

\author{
Kalashnikov A.O. \\ Geological institute KSC RAS, Apatity, kalashnikov@geoksc.apatity.ru
}

\begin{abstract}
The universal approach to automatic three-dimensional geological mapping is described. It is suitable for different types of data, ore objects of different genesis and structure. The approach consists of the following steps: (1) selection of variables that determine rock types quite accurately, (2) geostatistical analysis and interpolation of these variables into a block model, (3) finding a function that converts these variables to rock types and its application, (4) visualization. The proposed approach can be used for mineralogical and geochemical data; for cases when there is reference sampling of rock types and when there is no such sampling. Automatic 3D mapping of fault networks is also possible. The developed approach was tested on three ore objects of various structures and genesis: Kovdor baddeleyite-apatite-magnetite deposit (phoscorite-carbonatite stock), Lovozero eudialyte deposit (nepheline syenite lopolith) - Murmansk region, Bolshetroitskoe high-grade iron ore deposit (weathered crust of BIF, Belgorod region).
\end{abstract}

Key words: geological mapping; ore deposits; Kovdor massif; Lovozero massif; Belgorod iron ore district.

Технологии пространственного анализа и картирования бурно развиваются с начала 21 века. Однако, геологические карты существенно зависят от субъективных факторов, таких, как теоретический базис авторов, принятая концепция происхождения геологического объекта и т.п. Подобная проблема присутствует и при построении трехмерных геологических моделей, что особенно важно для моделирования месторождений, поскольку модель влияет на подсчет запасов, стратегию добычи и, следовательно, на рентабельность разработки месторождения в течение всего времени его эксплуатации. Одним из путей к минимизации влияния подобных факторов на модели месторождений является автоматизация моделирования. Несмотря на значительный прогресс в автоматизации и общую ориентированность на data-driven подход, для большинства методов автоматического картирования и моделирования требуются серьезные экспертные решения, априорные правила или отрисованные вручную опорные разрезы (Calcagno et al., 2008; Kessler et al., 2009; Ming et al., 2010). Для преодоления этой проблемы я разработал подход, который позволяет моделировать геологический объект, исходя почти исключительно из эмпирических данных.

Общая последовательность действий:

1. Выбор переменных, на основании которых можно определить тип пород. 
2. Геостатистический анализ каждой переменной.

3. Интерполяция всех переменных в единую блочную модель.

4. Нахождение функций, переводящий набор данных (для конкретной точки) в тип породы.

5. Приложение найденной функции к каждому блоку блочной модели.

6. Визуализация результата.

Наиболее сложным и нетривиальным шагом является п. 4, и не всегда эта задача решается. Ситуации с нахождением этих функций можно описать, по возрастанию сложности их нахождения, следующим образом.

В идеальном случае, для рудного объекта имеется набор достаточно плотно и равномерно расположенных данных о модальном содержании породообразующих минералов в породе, и к тому же для данного класса пород имеется общепринятая международная классификация по модальному составу. В итоге, автоматическое 3D картирование сводится к интерполяции модального содержания каждого минерала и применении существующей классификации к каждому блоку.

Следующий по сложности случай (и, видимо, наиболее распространенный) - имеется набор данных, косвенно отражающих модальный состав пород - это обычно массово определяемый химический состав пород и/или результаты геофизического исследования скважин; плюс имеется набор гораздо более редко отобранных эталонных проб, для которых определен модальное содержание минералов и тип пород. Таким образом, требуется найти функцию, переводящую химический состав пород (и/или их физические свойства) в тип пород по эталонной выборке. Эта задача известна в технологической минералогии как chemistry-to-mineral conversion (см., например, (Whiten, 2007)).

И самый сложный случай, когда эталонной выборки нет или она некондиционная (определения пород описательные, проведены на глаз и т.п.). Тогда приходится решать задачу кластеризации данных.

Для обоснования предлагаемого подхода мы опробовали его на данных, отражающих все перечисленные случаи. При этом для исследования были выбраны принципиально разные рудные объекты - Ловозерское эвдиалитовое месторождение (лакколит нефелиновых сиенитов), Ковдорское бадделеит-апатит-магнетитовое месторождение (фоскорит-карбонатитовый шток) - Мурманская область, и Большетроицкое месторождение богатых железных руд (кора выветривания железистых кварцитов, Белгородская область).

Самый простой случай - автоматическое 3D картирование Аллуайвского участка Ловозерского эвдиалитового месторождения. Исходными данными были количественные определения модального содержания породообразующих минералов (калиевый полевой шпат, нефелин, эгирин, амфиболы, эвдиалит) в породах Аллуайвского участка месторождения по микрофотографиям и BSE-изображениям комбинированных шлифов (275 образцов). Эти содержания непосредственно интерполировались в 3D блочную модель. Также учитывались и отдельно интерполировались два структурных признака - наличие мелкозернистой и пойкилитовой структуры. Пересчет минерального состава в типы пород проводился в соответствии Международной классификацией магматических горных пород (Le Maitre, 2002). Результат - широтный разрез Аллуайвского участка - показан на рисунке 1. С помощью предлагаемого подхода удалось выявить субгоризонтальное тело метасоматитов (предположительно реликт ксенолита пород ловозерской свиты) и зону мелкозернистых нефелиновых сиенитов в основании Эвдиалитового комплекса (Михайлова и др., 2019).

Следующий по сложности случай - Ковдорское бадделеит-апатит-магнетитовое месторождение (Мурманская область), приуроченное к одноименному фоскорит-карбонатитовому штоку. Густота опробования с непосредственным определением модального состава пород оказалась недостаточной для геологического моделирования в заданном масштабе, поэтому пришлось привлекать данные по химическому составу пород, с сетью опробования более чем в три раза плотнее. Исходными данными для геологического моделирования являлись результаты химического анализа пород (13 компонентов) по керну 108 скважин (1846 интервалов общей длиной около 30 км) и эталонное точечное опробование (550 образцов) с определением модального содержания породообразующих минералов (карбонаты, магнетит, апатит, форстерит) по микрофотографиям шлифов и 


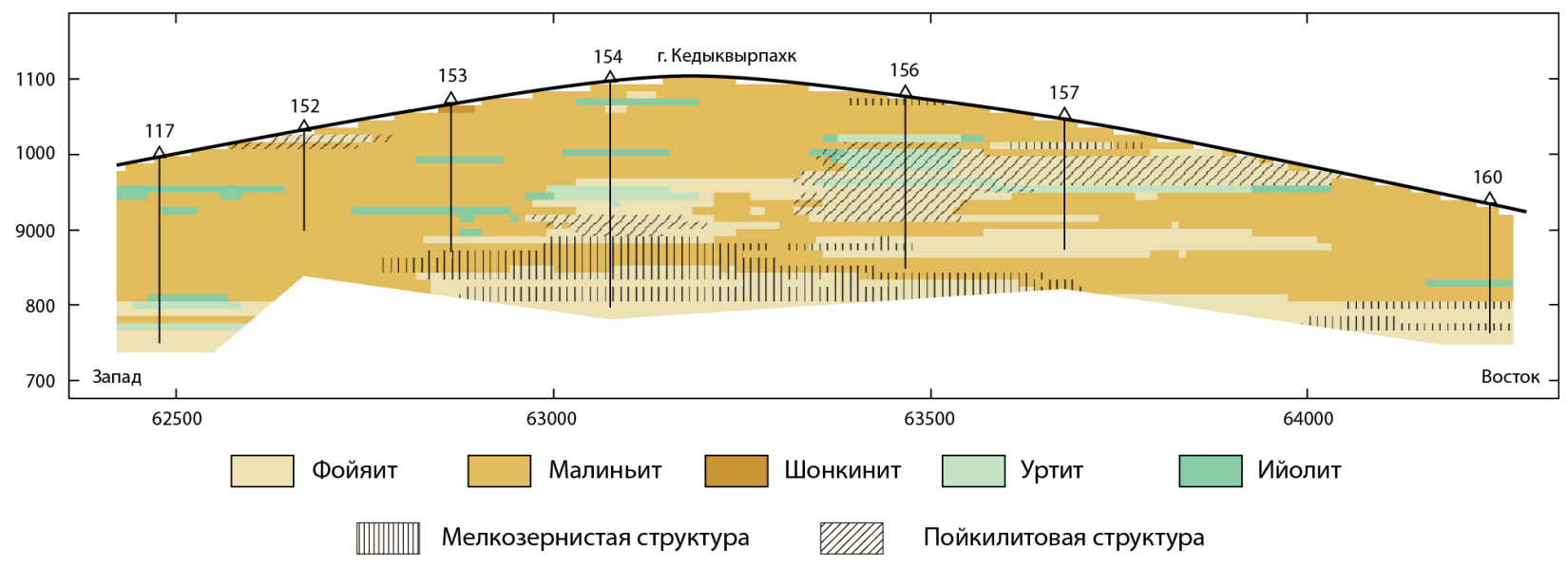

Рис. 1. Широтный разрез 3D геологической модели Аллуайвского участка Ловозерского эвдиалитового месторождения пород (Pakhomovsky et al., 2018).

Fig.1. Lattitudal cross-section of the 3D geological model of the Lovozero Eudialite deposit, the Alluaiv site (Pakhomovsky et al., 2018).
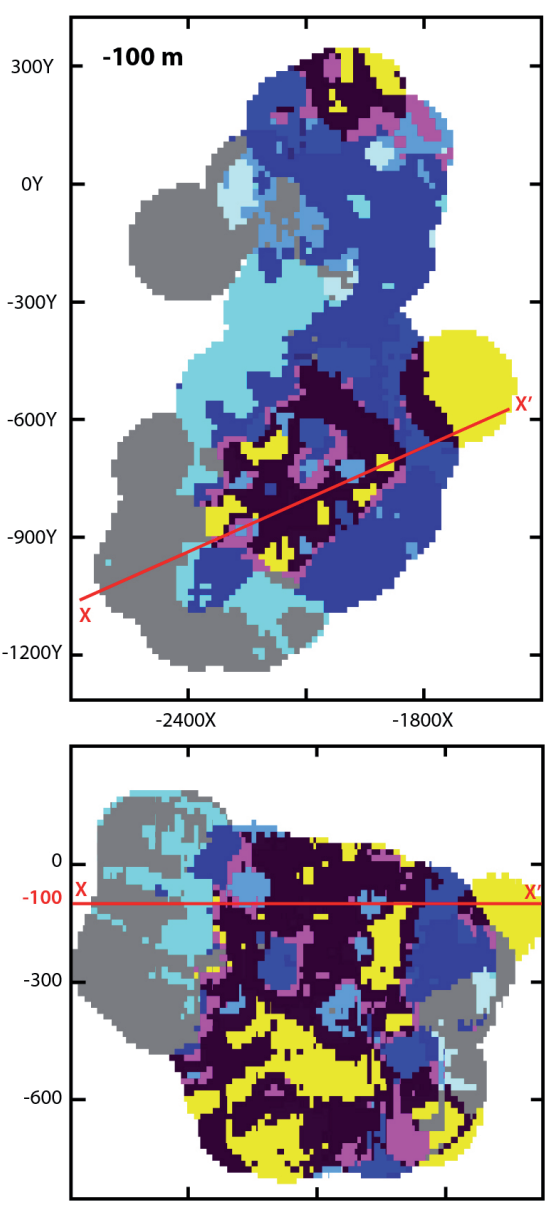

Рис. 2. Разрез и план 3D геологической модели Ковдорского бадделеит-апатит-магнетитового месторождения, по (Kalashnikov et al., 2017). Индексы в названии типов пород: $\mathrm{C}$ - карбонаты, $\mathrm{M}$ - магнетит, $\mathrm{A}$ - апатит, $\mathrm{F}$ - форстерит.

Fig. 2. Vertical and horizontal cross-section of the 3D geological model of the Kovdor baddeleyite-apatite-magnetite deposit (Kalashnikov et al., 2017).
BSE-изображениям. Далее с помощью метода искусственных нейронных сетей находилась функция, переводящая химический состав пород в минеральный, который, в соответствии с рекомендациями Международной классификации магматических горных пород, пересчитывался в тип пород (Kalashnikov et al., 2017). Вертикальное и горизонтальное сечений полученной 3D геологической модели показано на рисунке 2.

Большетроицкое месторождение богатых железных руд в коре выветривания железистых кварцитов (Белгородская область) - самый сложный случай для предлагаемого подхода. Визуальное определение минерального состава тонкозернистых, вторично измененных пород коры выветривания недостаточно точен для петрографически корректного названия пород, поэтому пришлось использовать только химический состав пород без эталонной («обучающей») выборки. Исходными данными являлись результаты химического анализа на 10 химических компонентов 1029 интервалов 28 скважин разведочного бурения (около 4 км керна). Разбиение на типы пород (задача кластеризации данных, «обучение без учителя») проводилось с помощью метода искусственных нейронных сетей - самоорганизующейся карты Кохоннена (Калашников, Никулин, 2018). Один из разрезов получившейся 3D геологической модели показан на рисунке 3. 


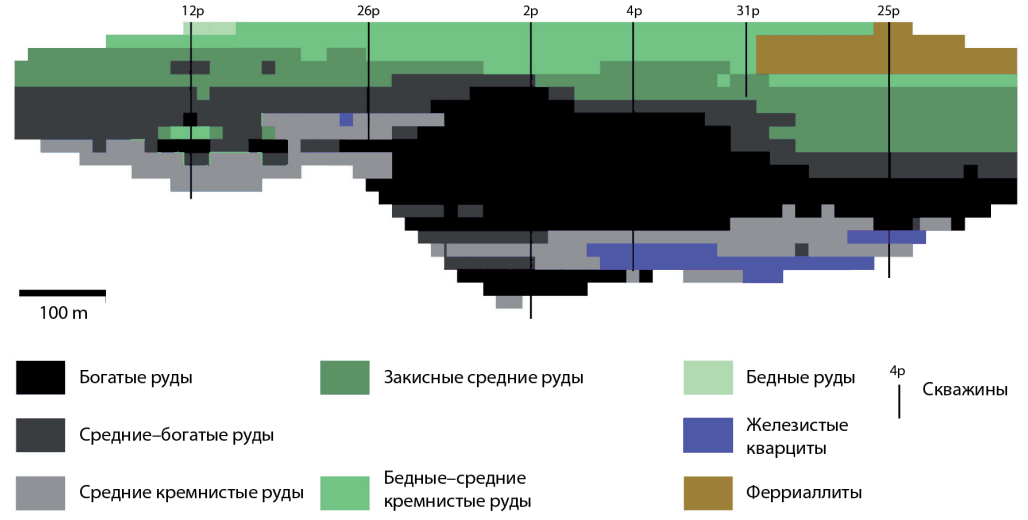

Рис. 3. Разрез 3D геологической модели Большетроицкого месторождения богатых железных руд, Белгородская область (Калашников, Никулин, 2018).

Fig.3. Longitudal cross-section of the 3D geological model of the Bolshetroitskoe high-grade iron ore deposit, Belgorod region (Калашников, Никулин, 2018).

В рамках развиваемого подхода можно также автоматически картировать и разломную сеть. Признаки разрывных нарушений, наблюдающиеся в керне скважин, интерполируются в блочную модель как вероятность их наблюдения (на шкале от 0 до 1). Полученный набор блоков со значением больше некоторого выбранного порога (например, 0.95) аппроксимируется набором поверхностей типа сплайн. Внутри каждого «тектонического блока» (т.е. блока, отделенного от других поверхностями разрывных нарушений) интерполяция прочих переменных (минеральный и химический состав пород, структурно-текстурные особенности) должна проводиться отдельно.

Исследование показало, что предлагаемый подход работает в широком диапазоне входных данных. Он применим для прямого пересчета минерального состава пород в типы пород; для косвенного определения типов пород по химическому составу пород - как с обучающей выборкой, так и без неё. Также он позволяет учитывать при картировании структурно-текстурные и другие «качественные» признаки. Дальнейшим направлением исследования будет являться применение подхода к картированию реальных разломных сетей и сложных складчатых толщах, как в двух, так и в трех измерениях.

Исследования проводились в рамках научной темы ГИ КНЦ РАН 0226-2019-0051 при финансовой поддержке Российским научным фондом, грант 16-17-10173.

\section{Литература}

1. Калашников А.О., Никулин И.И. Выделение типов пород по геохимическим данным с помощью искусственной нейронной сети (на примере Большетроицкого месторождения богатых железных руд, Белгородская область) // Труды Ферсмановской научной сессии. 2018. Т. 15. С. 168-171.

2. Михайлова Ю.А., Пахомовский Я.А., Калашников А.О., Яковенчук В.Н., Базай А.В., Иванюк Г.Ю. Циркониевая минерализация в аповулканитовых метасоматитах Ловозерского щелочного массива // Труды Ферсмановской научной сессии. 2019. № 16.

3. Calcagno P., Chilès J.P., Courrioux G., Guillen A. Geological modelling from field data and geological knowledge. Part I. Modelling method coupling 3D potential-field interpolation and geological rules // Physics of the Earth and Planetary Interiors. 2008. V. 171. P. 147-157.

4. Kalashnikov A.O., Ivanyuk G. Yu., Mikhailova J. A., Sokharev V. A. Approach of automatic 3D geological mapping: the case of the Kovdor phoscorite-carbonatite complex, NW Russia // Scientific Reports. 2017. V. 7. P. 6893.

5. Kessler H., Mathers S., Sobisch H.-G. The capture and dissemination of integrated 3D geospatial knowledge at the British Geological Survey using GSI3D software and methodology // Computers \& Geosciences. 2009. T. 35. № 6. C. 1311-1321.

6. Le Maitre R.W. (Ed.) Igneous Rocks. A Classification and Glossary of Terms. Recommendations of the International Union of Geological Sciences Subcommission on the Systematics of Igneous Rocks. New York: Cambridge University Press. 2002. 236 p.

7. Ming J., Pan M., Qu H., Ge Z. GSIS: A 3D geological multi-body modeling system from netty cross-sections with topology // Computers \& Geosciences. 2010. V. 36. P. 756-767.

8. Pakhomovsky Y.A., Panikorovskii T. L., Yakovenchuk V. N., Ivanyuk G. Yu., Mikhailova J. A., Krivovichev S. V., Bocharov V. N., Kalashnikov A. O. Selivanovaite, $\mathrm{NaTi}_{3}(\mathrm{Ti}, \mathrm{Na}, \mathrm{Fe}, \mathrm{Mn})_{4}\left[\left(\mathrm{Si}_{2} \mathrm{O}_{7}\right)_{2} \mathrm{O}_{4}\left(\mathrm{OH}, \mathrm{H}_{2} \mathrm{O}\right)_{4}\right] \cdot \mathrm{n} \mathrm{H}_{2} \mathrm{O}$, a new rock-forming mineral from the eudialyte-rich malignite of the Lovozero alkaline massif (Kola Peninsula, Russia) // European Journal of Mineralogy. 2018. V. 30. P. 525-535.

9. Whiten B. Calculation of mineral composition from chemical assays // Miner. Process. Extr. Metall. Rev. 2007. 29(2). P. 83-97. 